\title{
Atividades de leitura em livros didáticos de inglês: PCN, letramento crítico e o panorama atual
}

\author{
Reading tasks in EFL coursebooks: PCN, \\ critical literacy and the current panorama
}

Rogério Tilio*

Universidade Federal do Rio de Janeiro

Rio de Janeiro - Rio de Janeiro / Brasil

RESUMO: No componente curricular língua estrangeira, uma das orientaçôes mais controversas nos PCN EFII é o incentivo ao foco no ensino de leitura. Passados mais de dez anos da publicação dos $\mathrm{PCN}$, este trabalho analisa um livro didático de uma das duas únicas coleçôes didáticas aprovadas pelo PNLD 2011 para o ensino de inglês no segundo segmento do Ensino Fundamental, buscando entender como este livro aborda o ensino de leitura. Antes da análise proposta, é preciso não apenas discutir o discurso dos $\mathrm{PCN}$ e das leituras que deles vêm sendo feitas, mas também o conceito de letramento crítico, e os critérios do PNLD 2011 para a abordagem de leitura. Como a análise será feita com vistas ao letramento crítico, serão consideradas como categorias os tópicos abordados pelos textos, o trabalho com gêneros discursivos e a natureza das atividades propostas. A análise buscará discutir como os textos e atividades de leitura dialogam com os pressupostos teóricos dos PCN e do PNLD 2011.

PALAVRAS-CHAVE: leitura, ensino de inglês, letramento crítico, livro didático, atividades de leitura, PCN, PNLD 2011.

ABSTRACT: Concerning the teaching of a foreign language, one of the most controversial guidelines on the PCN EFII has been the focus on the teaching of reading. Considering that over ten years have passed since the $\mathrm{PCN}$ have been published, this article analyses a coursebook from one of the two only English series approved by the PNLD 2011 for the teaching of English in the second part of Ensino Fundamental, trying to understand how this book approaches the teaching of reading. Before the analysis, it is necessary to discuss not only the PCN discourse and its readings, but also the concept of critical literacy, and the PNLD 2011 criteria to teaching reading. Since the analysis aims at critical literacy, the article takes as analytical categories the topics of the texts, the work with

*rogeriotilio@gmail.com 
discourse genres and the nature of the proposed activities. The analysis intends to discuss how the texts and reading activities establish a dialogue with the theoretical principles of the PCN and the PNLD 2011.

KEYWORDS: reading, English teaching, critical literacy, coursebook, reading activities, PCN, PNLD 2011.

\section{Introdução}

Em 1997 o governo brasileiro, por meio do Ministério da Educação, começou a publicar os Parâmetros Curriculares Nacionais (PCN), uma série de documentos oficiais que propóem diretrizes com o objetivo de orientar o ensino na educação básica, tanto no Ensino Fundamental quanto no Ensino Médio. No componente curricular língua estrangeira, uma das orientaçôes que mais chama a atenção é o incentivo ao foco no ensino de leitura. Reconhecendo que, dentro da realidade da sala de aula da escola pública brasileira, o ensino das quatro habilidades linguísticas torna-se inviável, os PCN (1998) sugerem que, para que os alunos tirem proveito máximo do ensino da língua estrangeira, este deve ser focado em apenas uma habilidade linguística. Essa habilidade, idealmente, deve ser escolhida pelo professor, levando-se em consideração a realidade social de seus alunos. Nesse sentido, os PCN (1998) sugerem que a habilidade de leitura é a que mais alunos têm a maior chance de utilizar em sua vida fora da escola, pois os discursos escritos são, em geral, os mais acessíveis. Além disso, não se pode ignorar que, levando-se em conta a realidade da escola pública brasileira, a habilidade de leitura é a mais fácil de ser ensinada.

Passados mais de dez anos da publicação dos PCN, até onde chegamos? Será que a sala de aula de língua estrangeira incorporou os discursos dos PCN, no que diz respeito à abordagem de leitura? Para tentar responder essas perguntas, este trabalho analisa um livro didático de uma das duas únicas coleçôes didáticas aprovadas pelo Programa Nacional do Livro Didático de 2011 (PNLD 2011) para o ensino de inglês no segundo segmento do Ensino Fundamental ( $6^{\circ}$ ao $9^{\circ}$ ano), buscando entender como esse livro aborda o ensino de leitura. Mesmo reconhecendo que o livro didático ainda passe pela mediação do professor em seu uso na sala de aula, este ainda é tido muitas vezes como o "senhor" da sala de aula (DIAS; CRISTÓVÃO, 2009), ditando grande parte do comportamento do professor em aula (CORACINI, 1995; 1999); além disso, o livro reflete a concepção de leitura dos autores e a forma como intencionam trabalhá-las com os alunos. Esta análise levará em consideração tanto o livro didático em si quanto o Guia do PNLD 2011, que traz a resenha das coleções aprovadas. 
Antes da análise, entretanto, é preciso contextualizar o período em questão, a partir do discurso dos PCN, de 1998, e das leituras que deles vêm sendo feitas, desde então. Serão discutidos (a) a visão de linguagem e de aprendizagem que norteia o trabalho com leitura; (b) a ênfase na época atribuída à leitura; (c) questōes atuais e problematizaçōes inerentes a essa ênfase; (d) o conceito de letramento crítico; e (e) os critérios do PNLD 2011 para a abordagem de leitura. A análise será feita com vistas ao letramento crítico e, para isso, serão consideradas como categorias de análise os tópicos abordados pelos textos (TILIO, 2006; 2010), o trabalho com gêneros discursivos e a natureza das atividades propostas. A análise buscará discutir como os textos e atividades de leitura dialogam com os pressupostos teóricos dos PCN e do PNLD 2011.

\section{Teoria de leitura: PCN, letramento crítico e PNLD}

Antes de entrar no campo específico da leitura, é preciso caracterizar a língua estrangeira como objeto de ensino: o que significa aprender uma língua estrangeira e por que ensinar língua estrangeira na escola?

Em primeiro lugar, aprender línguas significa aprender conhecimentos e seu uso. A linguagem e a aprendizagem são aqui entendidas dentro de uma perspectiva sociointeracional, ou seja, situadas socialmente e construídas em interaçōes. A aprendizagem é uma forma de participação social na qual ocorre a construção de conhecimento compartilhado. Três tipos de conhecimentos estão presentes na construção do conhecimento da língua: conhecimento do sistema linguístico (conhecimento sistêmico), conhecimento da organização dos discursos na língua (conhecimento de organização textual) e conhecimento de mundo. É na projeção e interseção desses três tipos de conhecimento que significados são negociados e o conhecimento da língua é construído (BRASIL, 1998). Por isso, o ensino de língua estrangeira deve, ainda segundo os PCN LE, orientar-se pelo foco na compreensão global (escrita e oral) e pelo empenho na negociação do significado, e não na correção (BRASIL, 1998).

E por que ensinar língua estrangeira? Porque ela pode orientar e sensibilizar o aluno em relação ao mundo multilíngue e multicultural em que vive, conscientizando-o acerca de diferenças culturais e levando-o a respeitar mais o outro e conhecer melhor a si mesmo, uma vez que é por meio do olhar do outro que aprendemos a nos conhecer melhor. Além disso, o conhecimento dos discursos em língua estrangeira, mais especificamente o inglês, a língua franca da contemporaneidade, pode permitir maior acesso aos mais diferentes 
tipos de conhecimento no mundo globalizado contemporâneo. $\mathrm{O}$ acesso à língua estrangeira, portanto, pode permitir maior inclusão social no mundo globalizado.

É importante ressaltar que, paradoxalmente, o acesso a esses mesmos discursos também pode servir para empoderar aqueles que o têm, podendo a esses discursos resistir, lutando contra sua hegemonia. Esses mesmos discursos globalizados, que não são únicos, mas muitas vezes se pretendem assim, podem difundir uma ideologia hegemônica e alcançar e influenciar rapidamente grande parte da população em escala global, beneficiando a parcela da população a quem tal discurso interessa (MOITA LOPES, 2003). O conhecimento desses discursos pode empoderar seus conhecedores a resisti-los, construindo, então, uma outra globalização (SANTOS, 2000) que, em vez de globalizar a hegemonia, realmente abarca a pluralidade e a diversidade.

Moita Lopes (2003) destaca três aspectos dos PCN de língua estrangeira que reforçam o uso do inglês na vida contemporânea para construir novos discursos anti-hegemônicos:

a) a construção de uma base discursiva em que o aluno se envolva na construção do significado. Dessa forma, aprender uma língua deve ser entendido como aprender a se engajar criticamente nos significados produzidos na língua, reconhecer posicionamentos discursivos e saber que é possível construir novos significados para alterar esses posicionamentos, que às vezes são de exclusão;

b) o desenvolvimento da consciência crítica em relação à linguagem. O uso da linguagem envolve escolhas de possibilidades de significados através dos quais agimos no mundo e o constituímos; $\mathrm{e}$

c) o foco nos temas transversais, ou seja, em questóes que permeiam a vida social contemporânea: ética, trabalho, pluralidade cultural, meio ambiente, sexualidade, consumo e saúde. Professores e alunos podem enfocar práticas sociais vividas fora da escola, já que, ao usar a linguagem as pessoas constroem significados acerca destes temas transversais, construindo a si mesmas e o mundo social a sua volta. (Adaptado de MOITA LOPES, 2003).

O ensino de língua estrangeira pode ainda mostrar como os temas transversais são abordados nos discursos em língua estrangeira e propor uma transposição e problematização para o espaço social dos alunos. Não se trata de julgar ou comparar, mas de pensar criticamente as diferenças; é preciso propor uma reflexão com base em diferentes contextos. O ensino de língua estrangeira 
é um espaço privilegiado para a discussão de tais questōes, pois se trata do ensino de linguagem por meio do uso da linguagem. Cabe ao professor (e ao material didático) a escolha dos contextos de uso da linguagem: se abstratos ou se sócio-historicamente situados.

Nessa perspectiva, o ensino de língua estrangeira envolve uma série de questôes que extrapolam a organização sistêmica: escolhas temáticas, escolhas de organização textual (gêneros discursivos e mecanismos de coesão e coerência), variação lingüística e pluralidade cultural. A língua estrangeira assume, assim, um papel educacional e pragmático para a construção da cidadania, servindo de instrumento de libertação e inclusão social (BRASIL, 1998).

Para alcançar tais objetivos de efetivamente permitir que o aprendiz atue no mundo usando a língua estrangeira, os conteúdos propostos devem propiciar seu engajamento discursivo. Segundo os PCN LE, isso envolve a aprendizagem de estratégias de construção do significado via língua estrangeira e o foco em habilidade(s) linguística(s): compreensão escrita, compreensão oral, produção escrita e produção oral. Duas questôes precisam ser aqui problematizadas: o conceito de habilidades linguísticas e o foco nas quatro habilidades.

$\mathrm{O}$ uso do termo habilidades linguisticas explica-se aqui pelo seu largo emprego na área de ensino de línguas estrangeiras. Por estar relacionado a teorias de comportamento (ROJO, 2009), o termo habilidades é muitas vezes preterido por termos como competências, ligado a algumas teorias de inteligência e de desenvolvimento humano, e capacidades (perceptuais, motoras, cognitivas, afetivas, sociais, discursivas, linguísticas), muitas vezes preferidos por extrapolarem um aspecto meramente automatizado, aparentemente embutido na palavra habilidades. Entretanto, habilidades linguísticas é um jargão que vem sendo largamente utilizado em teorias de aprendizagem desde o advento da chamada abordagem comunicativa, que, no seu início, caracterizava-se por marcar um espaço anticomportamentalista. Entendo aqui habilidades linguísticas como parte das competências e capacidades de um indivíduo, e sem qualquer conotação meramente comportamentalista; entendo as habilidades linguísticas especificamente como as capacidades (ou habilidades) linguístico-discursivas que um indivíduo desenvolve para ler, escrever, falar e ouvir em uma determinada língua, ou seja, para se comunicar com essa língua. Habilidades comunicativas e capacidades são, portanto, aqui entendidos como conceitos distintos, com o primeiro constituindo-se como parte do segundo. Ademais, leitura é aqui entendida como parte de um conceito maior, o de letramento crítico, que será discutido mais adiante. 
No entanto, antes de conceituar e discutir letramento crítico, é preciso problematizar um outro ponto levantado pelos PCN LE: em qual ou quais habilidades linguísticas o professor deve focar o ensino. Existe uma forte tendência dentre as metodologias de ensino de línguas estrangeiras, e consequentemente na produção de material didático para a área, a se enfocar as quatro habilidades linguísticas simultaneamente. Acredita-se que "saber uma língua" seja "saber ler, escrever, falar e ouvir" essa língua. Embora tal crença não seja inverídica, pode acarretar duas falsas crenças: a de que para saber uma língua é preciso dominar as quatro habilidades igualmente, e a de que tal conhecimento é bastante para o conhecimento da língua. No entanto, uma vez que os indivíduos não são iguais, o conhecimento que esses indivíduos têm também não pode ser igual, pois ele não é pronto, dado, mas construído na interação social. Diferentes indivíduos negociam e constroem significados de formas distintas e diversas. O conhecimento de uma língua não é, portanto, homogêneo: suas habilidades linguísticas variarão de acordo com suas realidades e suas necessidades. Em outras palavras, nem todos os falantes de uma língua são igualmente proficientes. E mesmo um alto grau de proficiência nessas quatro habilidades não assegura ao indivíduo competência comunicativa na língua (HYMES, 1972): além da competência linguística, são necessárias as competências discursiva, sociolinguística e estratégica (CANALE; SWAIN, 1980).

Os PCN LE entendem, no entanto, que, por restrições de carga horária semanal e de número de alunos em sala de aula, como na realidade da escola pública brasileira, não é possível trabalhar de forma satisfatória todas as competências/capacidades ideais; recomendam, portanto, que o professor enfoque apenas uma habilidade linguística, pois é preferível que o aluno domine bem mesmo que apenas uma das habilidades do que as quatro de maneira precária. Trata-se, no entanto, apenas de um foco; ou seja, as demais habilidades não são descartadas, mas trabalhadas a partir do foco em uma determinada habilidade. ${ }^{1}$ Também não são descartadas as capacidades, visto que, como já discutido anteriormente, o trabalho com habilidades necessariamente pressupõe a articulação de diversas capacidades. A escolha da habilidade a ser enfocada cabe ao professor, que deve escolhê-la com base nas necessidades e na realidade dos alunos.

\footnotetext{
${ }^{1}$ Interpretações equivocadas dos PCN dão conta de que este sugere foco exclusivo na leitura. Trata-se, no entanto, apenas de uma sugestão de ênfase, dada a necessidade "logística" de ênfase em alguma(s) habilidade(s) e a função social da leitura, conforme explicado acima.
} 
Os PCN LE sugerem que, em geral, essa habilidade seria a leitura, uma vez que esta seria a que atingiria mais democraticamente a maior parte da população. Mesmo sem ter a oportunidade de viajar ao exterior, $\mathrm{o}$ aluno pode se beneficiar da habilidade de leitura em língua estrangeira, especialmente em inglês, uma vez que grande parte do conhecimento é veiculada em inglês, principalmente pela internet. Além disso, a habilidade de leitura em língua estrangeira tem, no Brasil, uma outra função instrumental de acesso ao conhecimento: as provas de acesso ao Ensino Superior, tanto nos níveis de graduação quanto de mestrado e doutorado, incluem provas de leitura em língua estrangeira.

E como trabalhar a habilidade de leitura? Trata-se de uma tarefa complexa, pois o processo de leitura, em uma abordagem sociointeracional (aquela adotada pelos PCN LE), envolve diversas capacidades simultâneas: reconhecimento, decodificação, compreensão, interpretação e transposição social. Em outras palavras, durante o ato de ler, o leitor precisa a) reconhecer o código linguístico utilizado (note-se que reconhecer não significa necessariamente conhecer); b) estar apto a "traduzi-lo", mesmo que de forma tentativa (embora não seja preciso conhecer todos os elementos linguísticos, é preciso reconhecer ou inferir elementos para que haja algum entendimento); c) entender a mensagem veiculada pelo texto e ser capaz de problematizá-la; d) transpô-la para a vida social. Embora essas sejam capacidades simultâneas, há uma tendência de entendê-las como lineares, partindo do reconhecimento e culminando na vida social. A proficiência do leitor em cada uma dessas capacidades varia, com um melhor desempenho em algumas, compensando pelo menor desempenho em outras. No entanto, a ausência total de alguma delas certamente dificulta o processo de leitura.

Atividades de leitura em livros didáticos devem, idealmente, dar oportunidades para que os aprendizes pratiquem todas essas capacidades. É verdade que as capacidades de interpretação e transposição para a vida social, de certa forma, pressupōem as capacidades de reconhecimento, decodificação e compreensão. Por esse motivo, é possível compreender se um livro didático optar por privilegiá-las. O inverso, no entanto, não se aplica: explorar reconhecimento, decodificação e compreensão não garantem que o aprendiz vá desenvolver capacidades de interpretação e transposição para a vida social.

Portanto, ao privilegiar as capacidades de interpretação e transposição para a vida social, dois elementos precisam ser levados em consideração ao se analisar atividades de leitura em livros didáticos: a escolha dos textos e as atividades propostas para sua exploração, pois são essas que possibilitarão a 
maior interface da leitura com a vida social. Em primeiro lugar, é preciso problematizar o material objeto de análise: os textos. Sua relevância e adequação ao público-alvo e aos objetivos educacionais são fundamentais para uma perspectiva sociointeracional de aprendizagem. Os tópicos abordados nos textos são, portanto, requisitos essenciais para que o aluno possa negociar significados e construir conhecimento. Como o livro didático não está presente na sala de aula sem mediação de professores e alunos, mesmo que as atividades propostas não trabalhem os tópicos de maneira crítica e reflexiva, sua presença no livro pode servir de estímulo para este trabalho. Por outro lado, sua simples presença não pode garantir que um trabalho crítico será desenvolvido. Embora nada possa oferecer esta garantia durante a mediação, se as atividades seguirem esta linha, maiores as chances dos professores se engajarem.

O enfoque na leitura aqui neste trabalho, portanto, é feito pelo viés do letramento crítico, pois este é compatível com uma teoria sociointeracional de linguagem e de aprendizagem na medida em que trata a leitura como uma prática sociocultural. Em um "trabalho de leitura que visa ao letramento crítico, ganham ênfase as representações e as análises a respeito de diferenças, tais como: raciais, sexuais, de gênero e as indagaçôes sobre quem ganha ou perde em determinadas relaçôes sociais" (BRASIL, 2006, p. 116). Conforme já discutido anteriormente, este enfoque no letramento crítico não despreza o trabalho com leitura que envolve reconhecimento, decodificação e compreensão, mas o estende à interpretação e transposição social, de forma a fazer da atividade de leitura realmente uma prática social.

As questóes que buscam desenvolver o letramento crítico levam em conta o trabalho que vinha sendo realizado em leitura nas escolas nos últimos anos. Ou seja, continua-se trabalhando a compreensão geral, dos pontos principais e as informaçôes detalhadas do texto, assim como os elementos lingüístico-textuais oferecidos pelos textos selecionados, os quais contribuem para a compreensão e o exercício de interpretação (construção de sentidos). O letramento crítico representa uma ampliação e uma definição desse trabalho de leitura no que se refere à expectativa de desenvolvimento crítico dos alunos. (BRASIL, 2006, p. 117).

São pressupostos do letramento crítico (adaptado de BRASIL, 2006, p. 117):

- o conhecimento não é natural ou neutro; baseia-se em regras discursivas de cada comunidade - logo, o conhecimento é ideológico; 
- a realidade não pode ser conhecida de forma definitiva, não podendo ser "capturada" pela linguagem; a "verdade" não se encontra na realidade, devendo ser compreendida em um contexto localizado;

- o significado nunca é dado; é sempre múltiplo, negociável, contestável, (re/co)construído cultural e historicamente, considerando-se as relações de poder envolvidas nas práticas sociais;

- o desenvolvimento de consciência crítica, que leve o aprendiz a adotar um comportamento proativo em relação a sua aprendizagem, questionando sua inserção social e estabelecendo relaçōes entre o que aprende e sua função social como cidadão agente de transformações.

Corroborando com a concepção de leitura discutida até então, o PNLD 2011 operacionaliza tais pressupostos teóricos por intermédio dos seguintes critérios para a avaliação de textos e atividades de leitura em livros de língua estrangeira (BRASIL, 2010, p. 16-17):

Coletânea de textos orais e escritos

- São apresentados textos representativos de diferentes esferas de atividade social?

- São apresentados textos de tipos e gêneros diferentes?

- São apresentados textos não verbais e textos que integram as modalidades verbal e não verbal?

- Os textos apresentam diversidade de suportes originais (revistas, almanaques, jornais, sítios da internet, periódicos científicos etc.)?

- Os textos contemplam a produção cultural específica para jovens e adolescentes?

- Os textos são representativos da heterogeneidade cultural e linguística, variedades (regional, urbana, rural etc.) e registros (formal e informal)?

- Os temas dos textos contribuem para a ampliação dos horizontes culturais do aluno?

- Os textos são, em sua maioria, autênticos (isto é, circulam socialmente na cultura oral e escrita) e, se autorais, trazem a indicação da fonte de origem?

- Os fragmentos e adaptações mantêm unidade de sentido, trazendo indicação dos cortes realizados? 
Compreensão escrita

- As convenções e os modos de ler constitutivos de diferentes gêneros e tipos textuais são trabalhados nas atividades de leitura?

- O caráter polifônico dos textos e, portanto, a multiplicidade de vozes nele presente, é ressaltado através das atividades de leitura?

- O trabalho com a compreensão escrita envolve atividades de pré-leitura e pós-leitura?

- O trabalho com a compreensão escrita promove o desenvolvimento de estratégias, tais como localização de informação, produção de inferência, compreensão geral e detalhada do texto, entre outras?

- O trabalho com a compreensão escrita explora a intertextualidade e estimula alunos e professores a buscarem textos e informações fora do livro didático?

- O trabalho com a compreensão escrita prevê a pluralidade de interpretações?

- O trabalho com a compreensão escrita contribui para a formação de um leitor reflexivo e crítico?

- O trabalho com o texto literário estimula a leitura interpretativa e considera a experiência estética e a dimensão de prazer envolvidas na leitura literária, não ficando restrito a um aspecto linguísticogramatical específico?

As atividades com o texto literário estimulam o leitor a conhecer a obra da qual o texto faz parte e seu contexto histórico?

É com base, portanto, em uma concepção de leitura como prática sociocultural, com vistas ao letramento crítico, e de acordo com os atuais documentos oficiais (Parâmetros Curriculares Nacionais, Orientaçôes Curriculares Nacionais e Programa Nacional do Livro Didático), que será conduzida a análise das atividades de leitura do livro didático em questão.

\section{Análise de um livro de uma das coleções aprovadas pelo PNLD 2011}

O livro didático aqui analisado é o volume do $9^{\circ}$ ano da coleção Links, de autoria de Denise Santos e Amadeu Marques, publicado pela editora Ática em 2009. A coleção é uma das duas únicas coleções aprovadas pelo PNLD 
2011. A opção pelo volume do $9^{\circ}$ ano explica-se pelo fato deste ser o último ano do Ensino Fundamental II, segmento para o qual a coleção se destina. Acreditase, portanto, que, devido ao maior amadurecimento dos alunos, o trabalho com leitura defendido neste trabalho possa ser mais facilmente implementado. Isso não quer dizer que esse trabalho não possa ser iniciado mais cedo; muito pelo contrário: acredito que tais práticas de letramento deveriam estar presentes desde o início da formaçăo leitora do aprendiz. Mas é natural esperar que este trabalho evolua conforme o amadurecimento dos alunos.

Três categorias serão consideradas na análise da abordagem de leitura do livro didático: os tópicos dos textos, os gêneros discursivos e as atividades de leitura propostas. Apesar de reconhecer que a leitura se faz presente em diversos momentos do livro, mesmo quando esta não é o objetivo pedagógico principal, foram considerados para a análise apenas os textos e atividades da seção "Let's Read", por ser esta a seção que se propõe a trabalhar especificamente a habilidade de leitura. Espera-se, portanto, que essa seja a seção do livro que dedique maior comprometimento e cuidado com textos e atividades de leitura.

No QUADRO 1 encontra-se, de forma esquemática, um levantamento dos textos e das atividades de leitura encontrados no livro, ordenados por unidades. O objetivo desta figura é dar ao leitor um panorama do livro, de forma a situá-lo na análise que se segue.

\section{QUADRO 1}

Textos e atividades de leitura da seçẫo "Let's Read" de Links 9o ano

\begin{tabular}{|c|l|l|}
\hline \multicolumn{2}{|c|}{ Links 90 ano } \\
\hline Unidade & \multicolumn{1}{|c|}{ Texto } & \multicolumn{1}{c|}{ Atividades de leitura } \\
\hline 1 & $\begin{array}{l}\text { Entrevista } \\
\text { Minha profissão é testar escorregadores }\end{array}$ & $\begin{array}{l}\text { - Completar frases com uma de duas } \\
\text { opções dadas } \\
\text { - Discutir }\end{array}$ \\
\hline 2 & $\begin{array}{l}\text { Linha do tempo } \\
\text { Moda ao longo da história }\end{array}$ & $\begin{array}{l}\text { - Perguntar o que o aluno já sabia e o } \\
\text { que não sabia antes de ler o texto } \\
\text { (depois da leitura) }\end{array}$ \\
\hline 3 & $\begin{array}{l}\text { Quiz: hábitos do aluno com o telefone } \\
\text { Factfile: telefone celular }\end{array}$ & $\begin{array}{l}\text { - Responder o quiz } \\
\text { - Verdadeiro ou falso }\end{array}$ \\
\hline 4 & $\begin{array}{l}\text { Três textos de um parágrafo cada (gênero: ?) } \\
\text { Meio ambiente }\end{array}$ & \begin{tabular}{l} 
- Correlacionar o título ao texto \\
\hline
\end{tabular} \\
\hline
\end{tabular}




\begin{tabular}{|c|c|c|}
\hline 5 & $\begin{array}{l}\text { Gêneros: ? } \\
\text { É um mundo pequeno (Disney World) } \\
\text { Patrimônios da humanidade (Unesco) }\end{array}$ & $\begin{array}{l}\text { - Em duplas, cada aluno lê um texto e } \\
\text { conta ao colega sobre o texto que leu }\end{array}$ \\
\hline 6 & $\begin{array}{l}\text { Entrevista } \\
\text { O que adolescentes gostam sobre o Brasil }\end{array}$ & $\begin{array}{l}\text { - Retirar informaçōes } \\
\text { - Discutir }\end{array}$ \\
\hline 7 & $\begin{array}{l}\text { Tirinha } \\
\text { Assunto: ? }\end{array}$ & $\begin{array}{l}\text { - Múltipla escolha } \\
\text { - Identificar comunicação verbal e não } \\
\text { verbal }\end{array}$ \\
\hline 8 & $\begin{array}{l}\text { Poema, biografia, glossário: } \\
\text { Direitos civis dos negros }\end{array}$ & $\begin{array}{l}\text { - Inferir o assunto do poema } \\
\text { - Em duplas, cada aluno lê um texto e } \\
\text { conta ao colega sobre o texto que leu } \\
\text { - Relacioná-los com o poema } \\
\text { - Dizer qual o verso preferido do } \\
\text { poema }\end{array}$ \\
\hline 9 & $\begin{array}{l}\text { Coluna de aconselhamento em revista } \\
\text { Término de um relacionamento amoroso } \\
\text { com um parceiro agressivo }\end{array}$ & $\begin{array}{l}\text { - Explorar parcialmente o gênero } \\
\text { - Verdadeiro ou falso } \\
\text { - Discutir }\end{array}$ \\
\hline 10 & Esquete & $\begin{array}{l}\text { - Encenar o esquete dado } \\
\text { Uma piada (assunto: ?) }\end{array}$ \\
\hline
\end{tabular}

\subsection{Tópicos}

Identificar os tópicos abordados pelos textos é o primeiro passo em direção a uma visão de leitura que privilegie o letramento crítico. É preciso que os textos tragam assuntos de interesse e relevância para os aprendizes, caso contrário a função social da leitura parece ser anulada. Para proceder a essa análise dos tópicos presentes nas seções destinadas à prática de leitura, será utilizada a categorização proposta por Tilio (2006; 2010), descrita brevemente a seguir:

- tópicos inclusivos, que possibilitam a inserção do aluno no mundo que está sendo criado, e tópicos excludentes, que afastam o aluno desse mundo;

- tópicos tradicionais, com assuntos atemporais, e tópicos pós-modernos, que tratam de assuntos da contemporaneidade;

- tópicos globalizados, preocupados com a integração de diferentes contextos globais, e tópicos localizados, preocupados apenas com questôes setoriais que parecem não atingir o âmbito da globalização;

- tópicos descontextualizados, tratados de forma genérica, como se válidos para qualquer situação, e tópicos contextualizados, inseridos em contextos culturais ou situacionais; 
- tópicos etnocentristas, que induzem à ideia de que determinadas culturas sejam superiores às demais, e tópicos multiculturais, que reconhecem a pluralidade cultural e suas diferenças inerentes;

- tópicos estereotipadores, que, na tentativa de reconhecer a diversidade, atribuem identidades essencialistas a determinados grupos, e tópicos diferenciadores, que tratam de diferenças que coexistem, sem se preocupar com a atribuição de identidades uniformes;

- tópicos conscientizadores, com o intuito de educar o aluno e o cidadão, muitas vezes com foco nos temas transversais apontados pelos PCN (meio ambiente, trabalho, saúde, ética, consumo, pluralidade cultural e orientação sexual), e tópicos alienantes, sem qualquer preocupação com a preparação do aluno para o mundo;

- tópicos legitimadores de identidades por meio da difusão de identidades socialmente aceitas, e tópicos que permitem a construção de identidades de projeto, por meio da resistência e sugestão de alternativas às identidades legitimadoras.

É importante ressaltar que as categorias acima, entretanto, não são dicotômicas. Não há uma polaridade, em que um tópico esteja localizado em um extremo ou outro. Trata-se de um contínuo, em que um mesmo tópico pode reunir características dos dois extremos, embora tendendo mais para um dos lados. Uma categorização também não exclui outras. Ou seja, um tópico pode reunir características de vários dos contínuos apresentados acima. Também é relevante notar que, dentro de um mesmo contínuo, não há necessariamente um extremo que seja "melhor" do que outro. É o caso dos contínuos tópicos tradicionais/pós-modernos, e tópicos globalizados/ localizados. Uma concepção que privilegia o letramento crítico deve abarcar os dois extremos desses contínuos, já que coexistem socialmente. Por outro lado, nos demais contínuos há sempre um lado que, acredita-se, deva ser evitado: tópicos excludentes, etnocentristas, estereotipadores, alienantes, e legitimadores de identidades socialmente privilegiadas.

Antes de começar, porém, vale a pena destacar as palavras dos autores do livro didático em análise sobre o assunto. Segundo o discurso da contracapa do livro, "a língua inglesa é apresentada em contextos que envolvem temas relevantes para o aluno brasileiro e oferecem situações de uso apropriadas à faixa etária" e "os temas abordados promovem a reflexão, o pensamento crítico e a formação de valores e atitudes para o exercício da cidadania” (SANTOS; 
MARQUES, 2009b). O mesmo discurso é retomado no Livro do Aluno, no qual os autores se dirigem aos alunos na seção "Welcome", afirmando que a obra "[estabelece] ligações [e apresenta] conexôes entre a língua inglesa e os temas que fazem parte [do mundo do aluno]" (SANTOS; MARQUES, 2009a, p. 3), e na seção "Apresentação" do Manual do Professor: "esta obra é organizada a partir de tópicos relevantes ao jovem aprendiz brasileiro" (SANTOS; MARQUES, 2009b, p. 3).

No entanto, não é isso que se observa no levantamento dos tópicos do livro do $9^{\circ}$ ano, conforme sistematizado no QUADRO 1. Merecem destaque os tópicos sobre meio ambiente e direitos civis dos negros, ambos conscientizadores. No entanto, o segundo passa praticamente despercebido. Há três textos na unidade: um poema, que trata a questão do racismo, uma biografia sobre o autor do poema e um glossário. As atividades propostas são: "descobrir" o assunto do poema, ler a biografia ou o glossário e trocar informaçôes com um colega que tenha lido o outro texto, bem como explicar quais os versos preferidos do poema. Ou seja, embora o tópico seja conscientizador e pertinente ao letramento crítico, o livro não o explora suficientemente, uma vez que não o coloca em discussão.

O livro apresenta ainda três tópicos pós-modernos e com potencial conscientizador, relevantes na contemporaneidade e merecedores de problematização e reflexão crítica: moda ao longo da história, telefone celular, comunicação não verbal e término de um relacionamento amoroso com um parceiro agressivo. No entanto, são tratados de forma superficial, alienante, sem a exploração de conflitos. Conforme será demonstrado nas próximas seções, o livro privilegia atividades que envolvem operações mentais simples, como reconhecer, decodificar e compreender. Vale lembrar que a presença do tópico em si pode despertar o professor para um trabalho crítico, mas o livro didático em questão não parece colaborar para tal. Soma-se a esses outro tópico alienante: um rapaz cuja profissão é testar escorregadores de água em Dubai. Será que se trata de uma profissão realmente relevante no contexto do aluno brasileiro, conforme os autores salientam na apresentação da obra?

Um tópico aparentemente multicultural é apresentado de maneira tímida na unidade 5: a diversidade cultural entre países. No entanto, por ser apresentado de maneira muito simplista, por meio de um texto sobre um passeio na Disney World e de outro da Unesco sobre patrimônios da humanidade, o tópico acaba se tornando estereotipador, pois resume as diferenças entre países a roupas típicas e monumentos ou belezas naturais. 
A unidade 6 trata de um tópico localizado: o que adolescentes gostam sobre o Brasil. Mais uma vez, o tópico torna-se estereotipador, pois são mencionadas apenas questôes óbvias sobre o Brasil, inclusive as já conhecidas internacionalmente, como belezas naturais, povo acolhedor, carnaval e violência. Ademais, não fica sequer claro no texto se os depoimentos dados são de brasileiros ou americanos, conforme será discutido na próxima seção.

Finalmente, a unidade 10 apresenta um texto sem tópico que, na categorização acima, chamo de tópicos descontextualizados. Trata-se de um esquete (os autores dizem que se trata de um esquete, mas não há marcas do gênero) com uma piada. O texto é uma piada no vácuo, e não parece explorar qualquer conteúdo temático. É, sem dúvida, relevante explorar o gênero piada, mas o texto escolhido deve ter algo a dizer, caso contrário deixa passar a oportunidade de inserir o aluno socialmente por meio do tópico e reduz o gênero a um conjunto de regras de organização estrutural imutáveis que independem do seu conteúdo temático. É a essa discussão acerca dos gêneros discursivos que passo logo a seguir.

\subsection{Gêneros discursivos}

Um primeiro olhar aos dados tabulados no QUADRO 1 pode parecer indicar uma diversidade de gêneros discursivos: entrevista, linha do tempo, quiz, factfile, tirinha, poema, biografia, glossário, coluna de aconselhamento em uma revista, esquete e piada. O Manual do Professor também reforça essa percepção: "a apresentação do conteúdo linguístico envolve variedade textual, de forma que o aluno possa ter contato com diferentes modalidades de linguagem em inglês (por exemplo, oral, escrita, visual) e diferentes gêneros textuais em inglês" (SANTOS; MARQUES, 2009b, p. 4). No entanto, todos os textos do livro são claramente não autênticos, chegando a ser artificiais, pois não deixam qualquer vestígio da função social dos gêneros e reduz seu conceito ao de uma organização estrutural fixa. ${ }^{2}$ Como ressalta o próprio Guia do PNLD 2011 de língua estrangeira,

\footnotetext{
${ }^{2} \mathrm{O}$ conceito de gêneros discursivos aqui utilizado é o de Bakhtin (1979), que reúne três elementos constitutivos: tema (contextualização sociohistorica), forma composicional (relaçôes heteroglóssicas e polifônicas) e estilo (organização textual).
} 
os textos utilizados nas atividades de leitura são, em sua maioria, elaborados especificamente para fins didáticos. Apesar de haver um empenho em caracterizar esses textos como pertencentes a gêneros, tipos e suportes midiáticos variados, raramente proporcionam ao aluno oportunidades de usar a língua de forma contextualizada ou de aprender sobre os modos de ler constitutivos dos gêneros específicos. (BRASIL, 2010, p. 45-46).

É o caso das entrevistas, presentes nas unidades 1 e 6 . Trata-se de um gênero importante de se trabalhar na escola, pois imagina-se que quase todos os alunos irão, algum dia, participar de uma entrevista, principalmente tendo em vista o mercado de trabalho. No entanto, as entrevistas apresentadas no material são artificiais, só podendo ser categorizadas como tal por apresentarem um conjunto de perguntas e respostas.

A primeira entrevista é com uma pessoa que trabalha testando escorregadores de água em Dubai, e se resume a três perguntas: o que uma pessoa que testa escorregadores de água faz, o que a fez querer ter esta profissão, e do que uma pessoa precisa para ter esta profissão. Apesar da indicação da fonte, a suposta entrevista está totalmente descontextualizada (FIG. 1): a diagramação do texto e as ilustrações não ajudam, por exemplo, a reconhecer de onde ela foi retirada. De um jornal? De uma revista? Foi uma entrevista feita pelos autores e transcrita no livro didático? Uma das ilustrações traz um rapaz escorregando, supostamente o entrevistado. No entanto, o rapaz está de costas e parece um adolescente se divertindo, não uma pessoa trabalhando. Como um texto pode ter credibilidade se suas diversas semioses não dialogam? Além disso, sabe-se que o nome da pessoa é Peter Doyle, mas essa pessoa existe mesmo ou é uma personagem criada pelos autores do livro didático? E mais: testar escorregadores de água é uma profissão realista? Existe mercado de trabalho para que várias pessoas se candidatem a uma vaga nessa profissão? É relevante trabalhar essa profissão de forma naturalizada, sem questionar suas especificidades e restrições? 

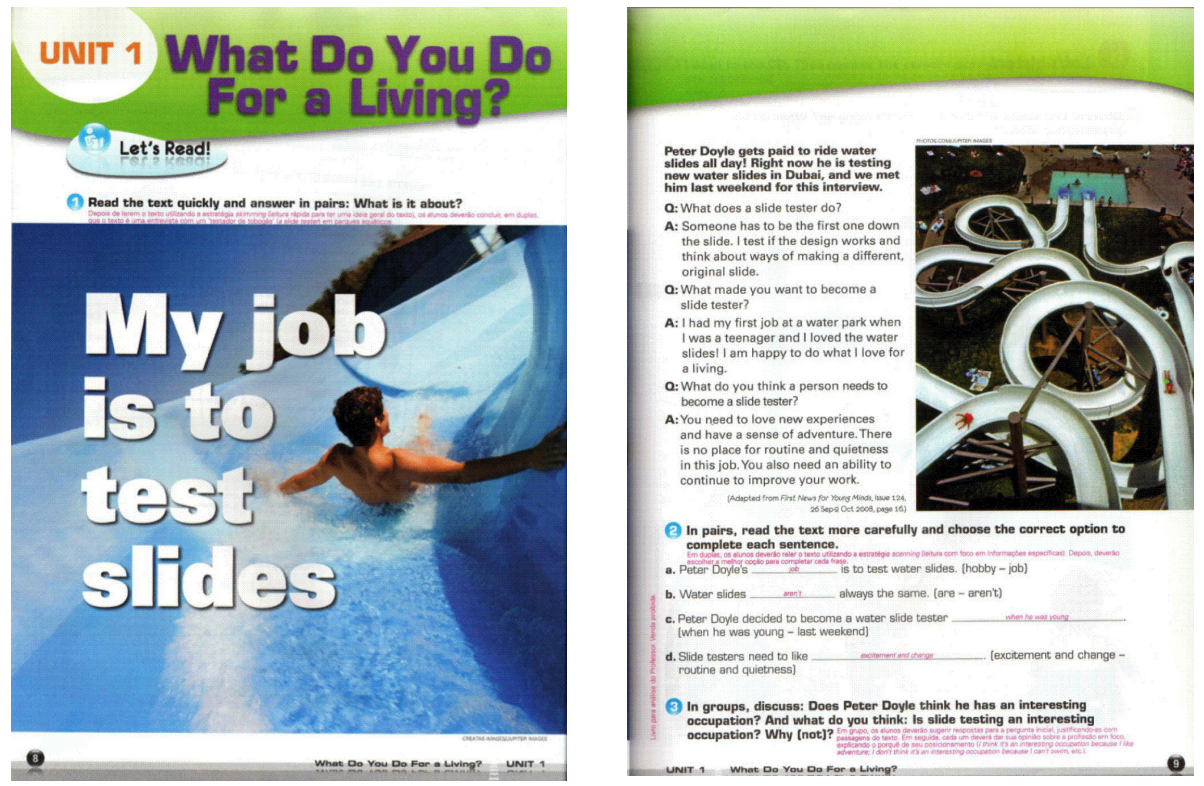

FIGURA 1 - Entrevista com a temática "profissão” no livro Links Fonte: Unidade 1, Links $9^{\circ}$ ano, p. 8-9.

A outra entrevista presente no livro está na unidade 6 (FIG. 2). Segundo o enunciado, foi retirada de uma revista para salas de aula americanas, Time for Kids. Traz uma pergunta - o que você gosta mais e menos a respeito do Brasil - e cinco adolescentes respondendo a essa pergunta.

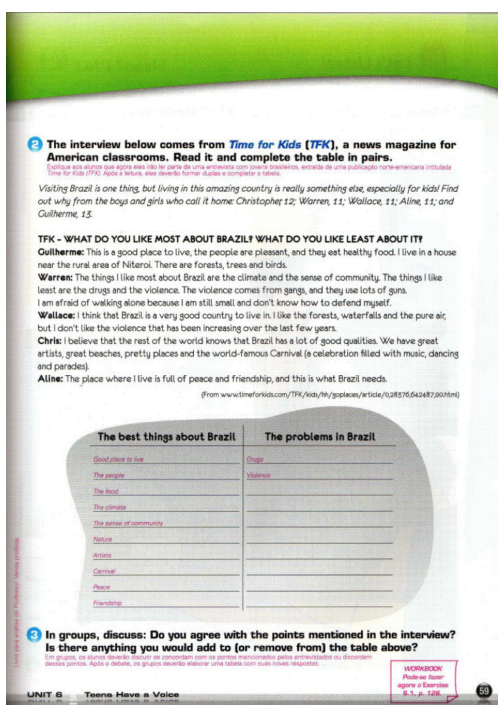

FIGURA 2 - Entrevista com a temática "Brasil" no livro Links

Fonte: Unidade 6, Links $9^{\circ}$ ano, p. 59. 
A introdução da entrevista parece deixar claro que os adolescentes moram no Brasil, mas não fica claro se são brasileiros falando de seu país ou americanos que moram no Brasil dando seus depoimentos sobre o país. Os nomes dos adolescentes aumentam ainda mais essa dúvida: Guilherme, Warren, Wallace, Chris e Aline. Apesar da indicação de fonte, a página referenciada não traz o mesmo conteúdo do livro didático.

Mesmo explorando o site, não foi possível encontrar os dados presentes no livro didático, o que contribui para a perda de credibilidade em sua autenticidade. Dados similares, no entanto, foram encontrados na entrevista "A Day in the Life", com um garoto brasileiro sobre sua rotina diária (FIG. 3). Tratase de dados mais factíveis do que os apresentados pelo livro didático.

\begin{tabular}{l}
\hline Sightseeing Guide \\
History Timeline \\
Native Lingo \\
Challenge \\
Day in the Life
\end{tabular}

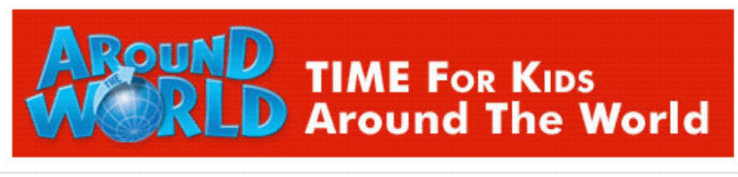

A Day in the Life: Brazil

What is it like to grow up in Brazil? Read about how one boy spends a typical school day.

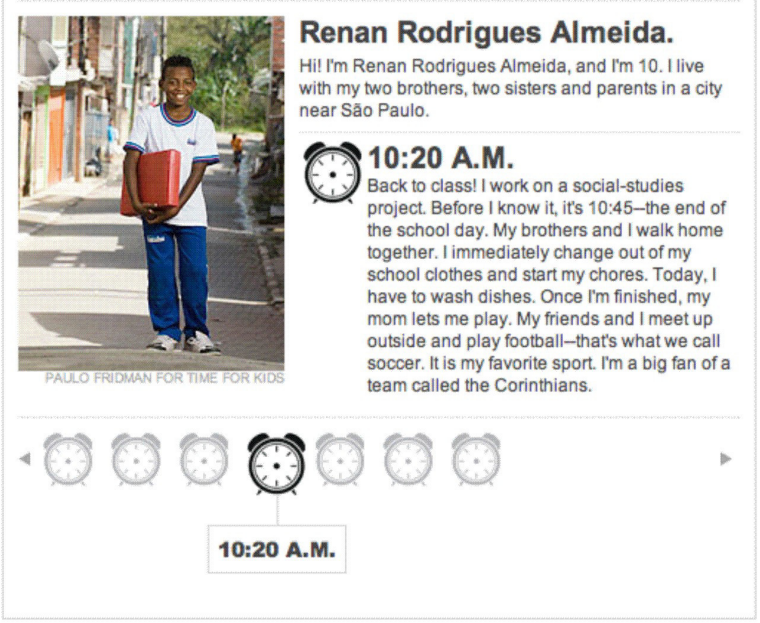

FIGURA 3 - Entrevista com a temática "rotina diária" no livro Links Fonte: <http://www.timeforkids.com/TFK/kids/hh/goplaces/article/ $0,28376,642436,00 \cdot h t m l>$. 
É interessante ressaltar que, em se tratando de uma fonte autêntica, a exploração do site poderia ser mais bem trabalhada no livro didático, uma vez que o site parece ser sólido, ou seja, não vai ser retirado do ar. Trata-se de um braço da revista Time com objetivos pedagógicos para crianças e adolescentes americanos, que tem seu conteúdo dividido por séries. Seria bastante produtivo incentivar os alunos a explorarem a publicação, especialmente o link "About us", ${ }^{3}$ no próprio site. Seria uma oportunidade de explorar mais uma prática de letramento, o letramento digital, em seus contextos naturais de produção e circulação - e em inglês, claro. Vale lembrar que o nome do livro didático aqui analisado é Links, o que remete imediatamente ao uso da internet. Tais conexōes, entretanto, não parecem ser encorajadas no livro, que, apesar do título, deixa de lado um importante elemento dos multiletramentos contemporâneos: o letramento digital.

Há ainda duas unidades no livro em que os textos apresentados não se enquadram em qualquer gênero (a não ser o didático): são apenas conjuntos de frases (que podem ser reconhecidos como pertencentes a um gênero didático apenas por estarem presentes em um livro didático). Na unidade 4, três parágrafos são apresentados para que os alunos os correlacionem com seus títulos. Tais parágrafos, entretanto, não apresentam qualquer suporte de gênero, além do didático, e, portanto, não parecem ter sido retirados de nenhuma fonte, mas escritos pelos autores para a obra didática (FIG. 4).

${ }^{3}$ http://www.timeforkids.com/TFK/teachers/about/0,28252,aboutus,00.html 

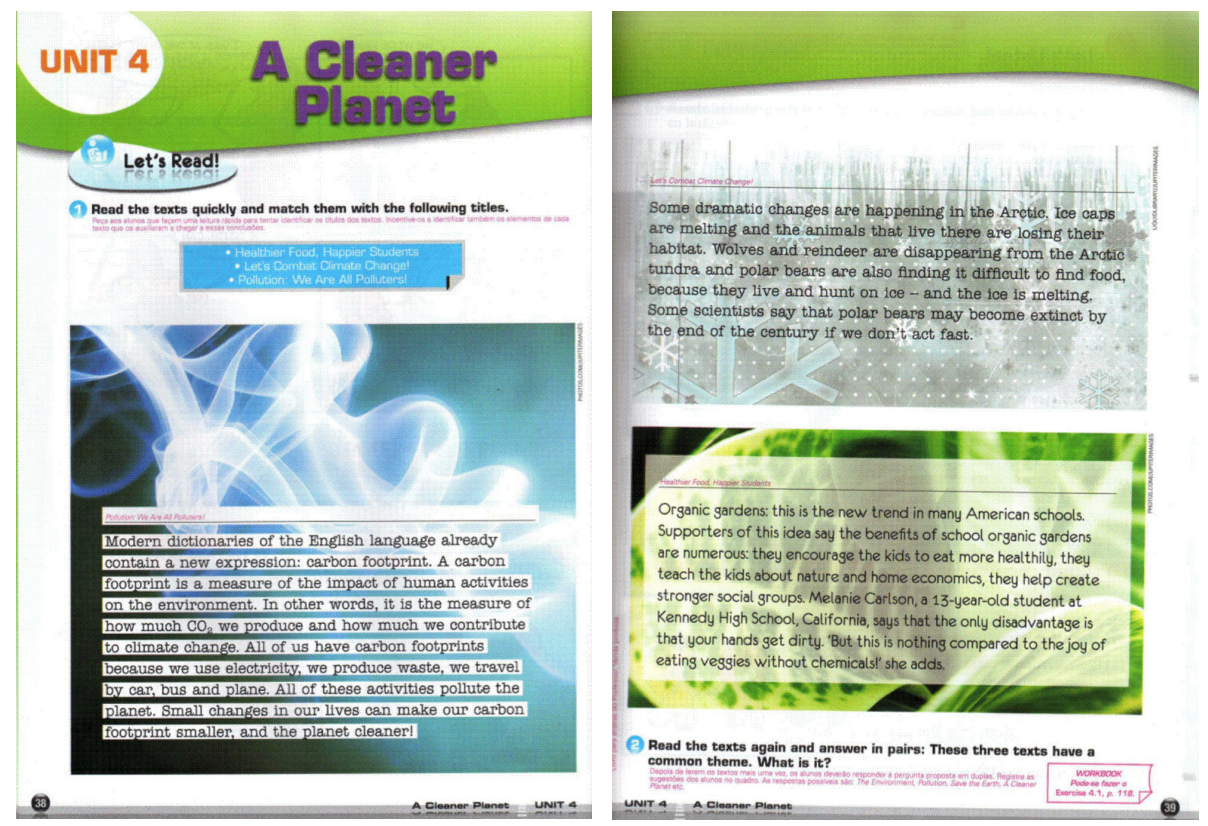

FIGURA 4 - Conjunto de textos na unidade "A Cleaner Planet", no livro Links Fonte: Unidade 4, Links $9^{\circ}$ ano.

O mesmo ocorre na unidade 5, embora nesse caso os autores tenham tentado enquadrar os textos em determinados gêneros por meio de ilustrações. Além dos textos para leitura, os autores apresentam ilustrações que pretendem mostrar sua inserção em uma página da internet e em um livro de referência, respectivamente, como mostra a FIG. 5. Tal artifício só reforça a ideia de que um gênero não passa de um enquadramento estrutural da informação. 

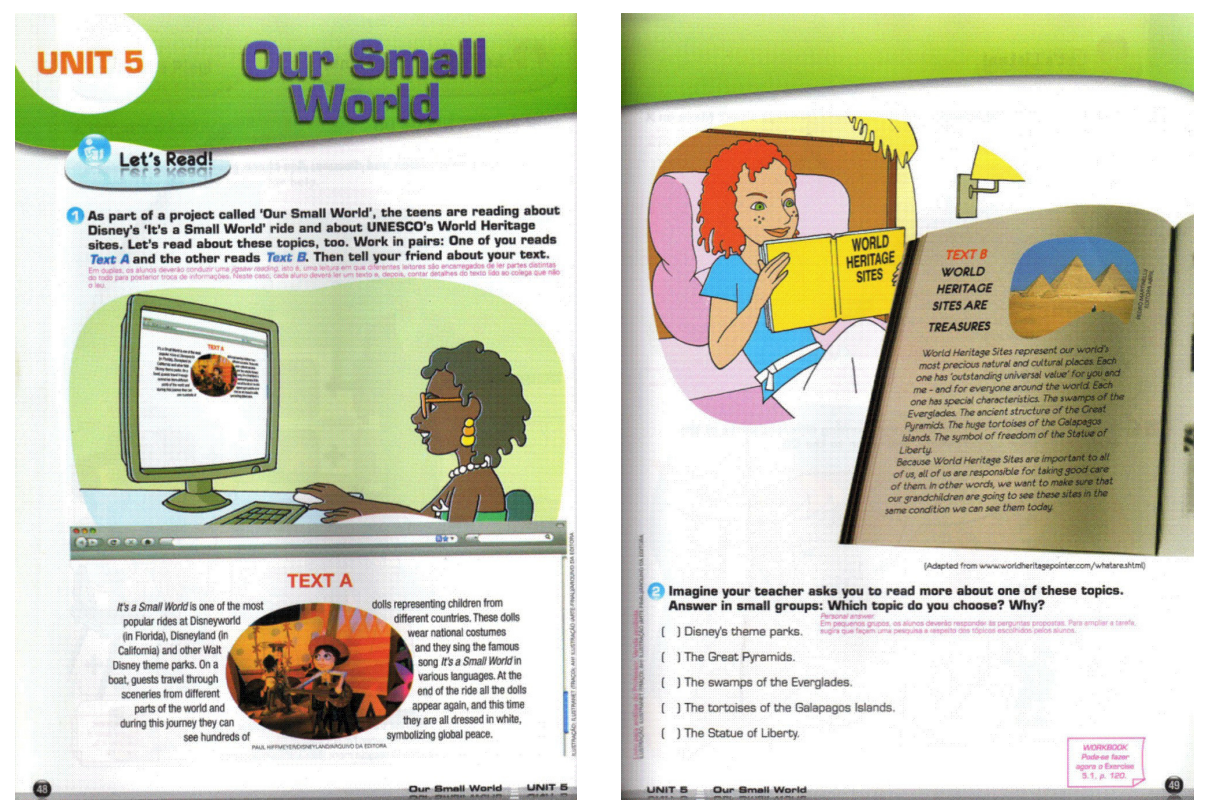

FIGURA 5 - Conjunto de textos na unidade "Our Small World" Fonte: Unidade 5, Links $9^{\circ}$ ano.

Esses e os demais gêneros presentes no livro didático têm um caráter meramente ilustrativo. Ou seja, aparentemente, os textos selecionados apresentam variedade de gêneros, mas nenhum trabalho é feito a esse respeito. Como o próprio Guia do PNLD 2011 de língua estrangeira reconhece em relação à coleção Links, "as questões propostas não resgatam o contexto de produção dos textos, isto é, não são dadas ao aluno informações sobre o autor, o suporte (jornal, revista, etc.) e os locais de circulação do texto" (BRASIL, 2010, p. 47). Pela natureza das atividades propostas, como será visto a seguir, o gênero é irrelevante, pois o texto é tratado meramente como materialidade linguística, de forma que o gênero em nada afeta o produto que os autores esperam como resultado dos exercícios.

\subsection{Atividades}

Chama a atenção a presença quase que exclusiva de atividades que exigem operações mentais simples em relação às atividades que demandam operações mentais mais complexas. O primeiro grupo inclui as atividades de leitura mais simples, que não envolvem correlações, ou seja, aquelas que envolvem apenas reconhecimento, decodificação e compreensão. No segundo 
grupo encontram-se atividades de interpretação e transposição social, que requerem capacidades além das operações mentais simples, tais como estabelecer conexões e refletir criticamente. Enquanto operações mentais simples focam apenas no produto, operações mentais complexas privilegiam o processo anterior ao produto.

O QUADRO 2 sistematiza a distribuição das atividades de leitura nessas duas categorias.

\section{QUADRO 2}

Categorização das atividades de leitura em Links $9^{\circ}$ ano

\begin{tabular}{|l|l|}
\hline \multicolumn{2}{|c|}{ Atividades de leitura em Links 9o ano } \\
\hline Operações mentais simples & Operações mentais complexas \\
\hline $\begin{array}{l}\text { - Completar frases com uma de duas } \\
\text { opções dadas }\end{array}$ & \\
- Perguntar o que o aluno já sabia e o & \\
que não sabia antes de ler o texto & \\
(depois da leitura) & \\
- Responder um quiz & \\
- Verdadeiro ou falso (2x) & - Discutir (3x) \\
- Correlacionar o título ao texto & - Explorar parcialmente o gênero \\
- Contar ao colega sobre o texto que leu (2x) & - Relacionar textos \\
- Retirar informações & - Inferir o assunto do poema \\
- Múltipla escolha & - Explicar o verso preferido do poema \\
- Identificar comunicação verbal e não verbal & \\
- Encenar um esquete dado & \\
\hline
\end{tabular}

Doze das dezenove atividades de leitura do livro, ou seja, 63\% envolvem apenas operações mentais simples, em que o aluno precisa apenas reconhecer informação do texto, sem problematizá-la. Dentre as sete ocorrências de atividades envolvendo operaçóes complexas, é preciso ressaltar que três delas são atividades de discussão (unidades 1, 6 e 9), que não trabalham o gênero discussão ou não o sistematizam como tarefa; são perguntas de pós-leitura, sempre após atividades envolvendo operações mentais simples (completar frases com uma de duas opções dadas, retirar informações, marcar verdadeiro ou falso) e apenas perguntando a opinião do aluno sobre o tópico do texto. Não se configuram, portanto, verdadeiramente como discussão. 
Outra atividade envolvendo operaçóes mentais complexas que merece destaque é a primeira atividade da unidade 9, que parece propor a exploração do gênero textual. Trata-se de uma coluna de aconselhamento de uma revista, com uma atividade de exploração do gênero e se resume a perguntar quem escreveu o texto, para quem, sobre o que ele fala e qual a sua provável origem. Embora pertinentes, são perguntas que deveriam preceder todos os textos do livro, não apenas esse em questão. No entanto, formular essas perguntas não garante um trabalho com o gênero, especialmente nesse caso, em que a essas perguntas seguem-se atividades que não exploram o gênero (marcar verdadeiro ou falso, e uma "discussão" que pergunta aos alunos se eles acham uma boa ideia (i) pedir ajuda na hora de terminar um relacionamento com um parceiro agressivo e (ii) terminar um relacionamento por $e$-mail). O trabalho com gênero foi abandonado, pois se poderia explorar a eficiência de se utilizar tal gênero em determinadas situações da vida social contemporânea. Além disso, o tópico, extremamente relevante (terminar um relacionamento com um parceiro agressivo), foi banalizado, servindo apenas de pretexto para uma atividade de identificar informações verdadeiras ou falsas e só sendo minimamente problematizado em uma pergunta de opinião - mesmo assim, no pé da página e seguida de outra pergunta irrelevante para o tópico: se seria uma boa ideia terminar um relacionamento por e-mail.

É importante observar ainda que em três das dez unidades (unidades 2, 5 e 10) não há uma preocupação com a preparação de atividades sistemáticas de leitura. Na unidade 2, a suposta atividade limita-se a perguntar ao aluno, após a leitura do texto, o que ele já sabia e o que não sabia antes de ler o texto. Na unidade 5 , os alunos devem trabalhar em duplas; cada membro da dupla deve ler um de dois textos e, em seguida, contar ao colega sobre o texto que leu. E, na unidade 10, pede-se que os alunos, após lerem um esquete, façam a sua encenação. Não há, portanto, trabalho de exploração da leitura nessas unidades.

Finalmente, vale ressaltar que cinco das dez unidades do livro (unidades $1,4,5,8$ e 9), ou seja, $50 \%$ delas, não fazem trabalho de pré-leitura, o que indica uma falta de preocupação com a ativação de conhecimentos de mundo do aprendiz e com a função social da leitura como prática social contextualizada. 


\section{Considerações finais}

Uma teoria de ensino e aprendizagem ancorada no letramento crítico defende que o objetivo da aprendizagem é possibilitar ao aluno agir no mundo social, entendendo-o melhor e podendo eventualmente vir a transformá-lo. Por meio da aula de língua estrangeira, especificamente, o aluno pode passar a ter acesso a novos conhecimentos e discursos que podem possibilitar sua inclusão no mundo globalizado. Além disso, um melhor conhecimento de outras culturas e de outros modos de vida ajuda em um melhor entendimento de si mesmo, de sua própria cultura e realidade.

Para viabilizar um trabalho nessa direção, na realidade da escola brasileira, principalmente a escola pública, devido a restriçōes de carga horária semanal e número de alunos em sala de aula, os PCN recomendam o foco em menos habilidades linguísticas, uma vez que um trabalho de boa qualidade fica praticamente inviabilizado em face às restrições acima. A escolha do foco precisa considerar as realidades e contextos específicos dos alunos e, em geral, no Brasil, com vistas à formação acadêmica e à inserção no mercado de trabalho, essa escolha tende a recair sobre a leitura.

A habilidade de leitura é aqui tratada na perspectiva do letramento crítico, como uma capacidade, mas o termo habilidade foi mantido para diferenciá-la das demais habilidades linguísticas. Essa perspectiva social de leitura prevê um trabalho com textos que abordem tópicos relevantes e inclusivos e que sejam contextualizados em seus gêneros discursivos e atividades que envolvam operações mentais complexas, tais como interpretação e transposição social. Dentro da perspectiva descrita acima, esperase que os textos selecionados para o material didático tragam:

i. tópicos relevantes, preocupados com a inclusão social do aluno no mundo globalizado;

ii. presença e variedade de gêneros discursivos, ressaltando sua função social e possibilitando o reconhecimento e a coconstrução de contextos sociais reais de uso, com vistas à ação e transformação;

iii. atividades de leitura que priorizem operações mentais complexas, estimulando o desenvolvimento do letramento crítico - construção social do conhecimento, da realidade, do significado e desenvolvimento de consciência crítica. 
Foi analisado o último volume de uma das duas únicas coleções aprovadas pelo PNLD 2011. Os resultados mostram que a maior parte dos textos traz tópicos alienados, sem se preocupar muito com a inclusão social do aluno no mundo globalizado. Apesar de aparentemente pertencerem a uma variedade de gêneros, os textos são claramente não autênticos, escritos especialmente para o livro didático com um objetivo pedagógico, e não retirados de contextos sociais reais de uso. Muitos dos textos são enquadrados visualmente de forma a parecerem pertencer a algum gênero, mas isso reforça o conceito equivocado de que um gênero discursivo resume-se a um conjunto de regras organizacionais fixas, sem se preocupar com sua função social. As atividades de leitura, por sua vez, envolvem, em sua maioria, apenas operaçôes mentais simples; mesmo aquelas que envolvem operaçóes mentais complexas parecem o fazer de forma acessória, complementar às atividades mais simples, e sem preparar adequadamente os alunos para realizá-las.

Destaco, a seguir, uma parte do texto da "Apresentação" do Manual do Professor, que expõe, segundo os autores, a teoria de ensino e aprendizagem supostamente adotada no livro didático:

[...] a obra favorece e incentiva constantes interações [...] fazendo uso da Língua Inglesa como um componente curricular que prepara o aluno para exercer sua cidadania e para qualificar-se para o mercado de trabalho.

A proposta pedagógica da coleção tem fundamento teórico nas concepções de língua, linguagem e aprendizagem articuladas nos Parâmetros Curriculares Nacionais (PCN). Especificamente, a coleção adota uma visão sociointeracional da linguagem, de acordo com a qual a comunicação é entendida como um processo relacionado a contextos de uso num dado momento histórico e social. Nesse cenário, a Língua Inglesa se insere não apenas como instrumento de comunicação, mas, sobretudo, como ponto de partida para reflexões sobre as funções da linguagem em práticas sociais mais amplas. Em paralelo, a coleção concebe a aprendizagem como um processo social de construção do conhecimento, em que professores e alunos interagem constantemente, participando, assim, ativamente do processo pedagógico.

A análise, no entanto, parece mostrar que tais pressupostos não são operacionalizados no livro do aluno - pelo menos no volume do $9^{\circ}$ ano. Fica, portanto, a pergunta: por que o livro foi aprovado para o PNLD, uma vez que ele não coloca em prática a abordagem sociointeracional dele esperada? Considero grave um livro que apresenta tantas lacunas em relação à proposta 
do PNLD ter sido aprovado. Até mesmo a resenha no Guia do PNLD, feita pelos próprios avaliadores, reconhece sua deficiência (ver a seção 3.2 do programa). Não seria uma contradição reconhecer a sua não adequação à proposta do edital e, mesmo assim, aprová-lo? Chamo a atenção para a ilustração abaixo (FIG. 6), retirada da página 20 do Guia do PNLD, e que traz um gráfico comparativo em cores, mostrando o nível de qualificação das coleções aprovadas. Note-se que o título discutido neste artigo (24925COL33, conforme FIG. 7) obteve notas próximas a zero em praticamente todos os itens. Como pôde uma coleção com tal índice de (des)qualificação ser aprovada?

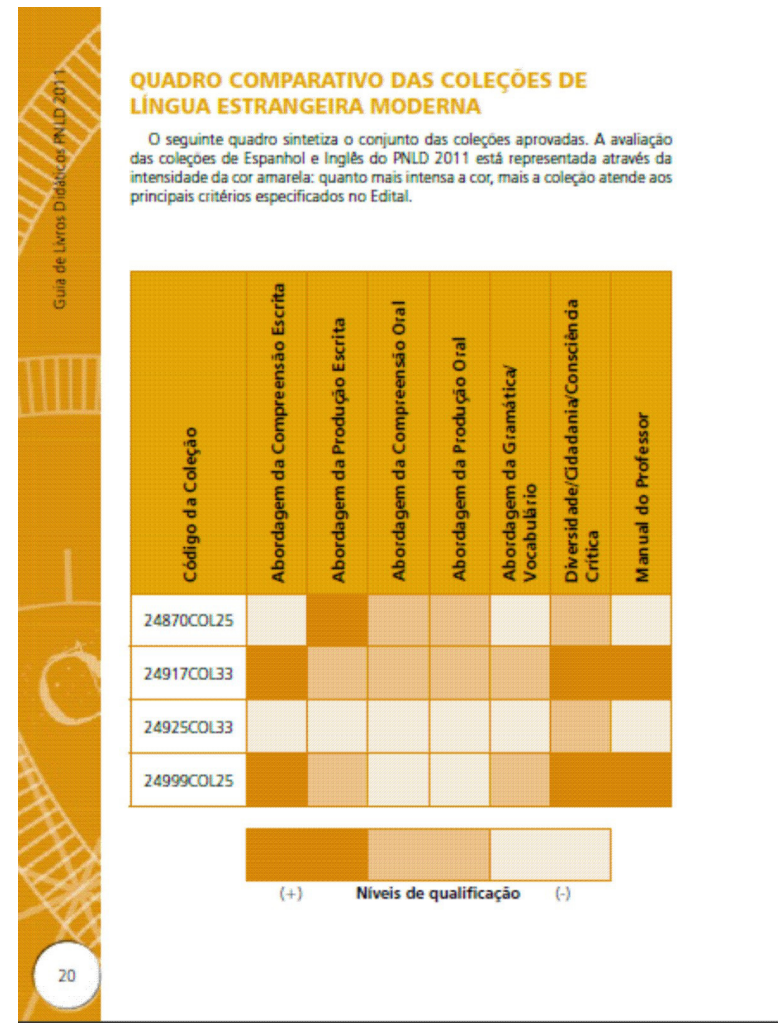

FIGURA 6 - Gráfico comparativo com o nível de qualificação das coleções aprovadas no PNLD LE 2011

Fonte: PNLD LE, 2011, p. 20. 


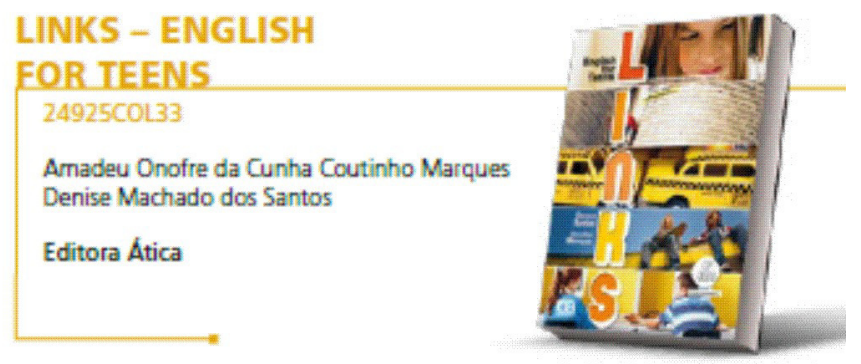

FIGURA 7 - Código PNLD do título analisado neste artigo Fonte: <http://www.fnde.gov.br/index.php/pnld-guia-do-livro-didatico >.

De fato, ao utilizar o livro, os professores podem adaptá-lo, tornando-o adequado a uma abordagem sociointeracional. Para isso, é preciso que estejam cientes das lacunas do livro, para que possam supri-las na preparação de suas aulas. Apesar de o Guia do PNLD apontar essas lacunas, é de se esperar que um material didático selecionado pelo PNLD atenda aos critérios de seleção. Se o MEC redige um edital, e ele próprio não o cumpre, coloca em risco toda a credibilidade do programa. Igualmente, é verdade que pela primeira vez foi feita uma avaliação do PNLD para a escolha e provimento de um livro de língua estrangeira para professores das escolas públicas - um desejo acalentado há muito tempo por professores - e que certamente deve-se esperar que, no próximo PNLD, haja mais livros concatenados com a proposta sociointeracional. Mudanças de paradigma ou implementação de novas práticas culturais levam muito tempo.

\section{Referências}

BAKHTIN, M. Estética da criação verbal. 4. ed. Rio de Janeiro: Martins Fontes, 2003. BRASIL. Ministério da Educação. Secretaria de Educação Básica. Guia de livros didáticos: PNLD 2011: Língua Estrangeira Moderna. Brasília: Ministério da Educação, Secretaria de Educação Básica, 2010. Disponível em: <http:// www.fnde.gov.br/index.php/pnld-guia-do-livro-didatico/2349-guia-pnld2011 . Acesso em: 4 jul. 2010.

BRASIL. Ministério da Educação. Secretaria de Educação Básica. Orientaçôes curriculares para o ensino médio. Brasília: Ministério da Educação, Secretaria de Educação Básica, 2006. v. 1: Linguagens, códigos e suas tecnologias. Disponível em:<http://portal.mec.gov.br/seb/arquivos/pdf/book_volume_01_internet.pdf>. Acesso em: 11 jan. 2008. 
BRASIL. Secretaria de Estado de Fazenda. Parâmetros curriculares nacionais: terceiro e quarto ciclos do ensino fundamental: língua estrangeira. Brasília: Ministério da Educação, Secretaria de Estado de Fazenda, 1998.

CANALE, M.; SWAIN, M. Theoretical Bases of Communicative Approaches to Second Language Teaching and Testing. Applied Linguistics, n. 1, p. 1-47, 1980. CORACINI, M. J. (Org.). Interpretação, autoria e legitimação do livro didático. São Paulo: Pontes, 1999.

CORACINI, M. J. (Org.). O jogo discursivo na aula de leitura. Campinas: Pontes, 1995.

DIAS, R.; CRISTÓVÃO, V. (Org.). Introdução. In: - O livro didático de lingua estrangeira: múltiplas perspectivas. Campinas: Mercado de Letras, 2009. p. 11-16.

HYMES, D. On Communicative Competence. In: PRIDE, J. B.; HOMES, J. (Ed.) Sociolinguistics. Harmondsworth: Penguin, 1972.

MOITA LOPES, L. P. A nova ordem mundial, os Parâmetros Curriculares Nacionais e o ensino de inglês no Brasil: a base intelectual para uma ação política. In: BARBARA, L.; ROCHA, R. C. G. (Org.). Reflexão e ações no ensinoaprendizagem de línguas. Campinas: Mercado de Letras, 2003. p. 29-57.

ROJO, R. Letramentos múltiplos, escola e inclusão social. São Paulo: Parábola, 2009. SANTOS, D.; MARQUES, A. Links: English for Teens - 9o ano. São Paulo: Ática, 2009a. Livro do Aluno.

SANTOS, D.; MARQUES, A. Links: English for Teens - 90 ano. São Paulo: Ática, 2009b. Manual do Professor.

TILIO, R. A representação do mundo no livro didático de inglês como língua estrangeira: uma abordagem sócio-discursiva. The ESPecialist, v. 31, n. 2, 2010. TILIO, R. O livro didático de inglês em uma abordagem sócio-discursiva: culturas, identidades e pós-modernidade. 2006. 258 f. Tese (Doutorado em Letras) Departamento de Letras, Pontifícia Universidade Católica do Rio de Janeiro, Rio de Janeiro, 2006. Disponível em: <http://www.maxwell.lambda.ele.puc-rio.br/ Busca_etds.php?strSecao=resultado\&nrSeq=8835@1>. Acesso em: 10 jul. 2010. TIME for Kids. A Day in the Life. Disponível em: <http://www.timeforkids.com/TFK/ kids/hh/goplaces/article/0,28376,642436,00.html>. Acesso em: 10 jul. 2010.

TIME for Kids. About us. Disponível em: <http://www.timeforkids.com/TFK/ teachers/about/0,28252,aboutus,00.html>. Acesso em: 10 jul. 2010.

Recebido em 09/09/2011. Aprovado em 12/01/2012. 